\title{
CORRECTION
}

View Article Online

View Journal | View Issue

Check for updates

Cite this: J. Mater. Chem. A, 2020, 8 , 6372

DOI: $10.1039 / d 0 t a 90062 a$

rsc.li/materials-a

\section{Correction: Machine-learning-assisted screening of pure-silica zeolites for effective removal of linear siloxanes and derivatives}

Shiru Lin, ${ }^{a}$ Yekun Wang, ${ }^{\mathrm{b}}$ Yinghe Zhao, ${ }^{\mathrm{a}}$ Luis R. Pericchi, ${ }^{\mathrm{b}}$ Arturo J. HernándezMaldonado*c and Zhongfang Chen ${ }^{\star a}$

Correction for 'Machine-learning-assisted screening of pure-silica zeolites for effective removal of linear siloxanes and derivatives' by Shiru Lin et al., J. Mater. Chem. A, 2020, 8, 3228-3237.

The authors regret that in the main manuscript and ESI, the unit for average loading was reported incorrectly. The correct unit for average loading should be "molecules per cell" instead of "mol" or " $\mathrm{mol}^{-1}$ ", which includes:

(1) Page 3229, right column, line 5, "average adsorption loading $\left(\mathrm{mol}^{-1}\right)$ " should be "average adsorption loading (molecules per cell)".

(2) Page 3230, left column, line 24, "average adsorption loading $\left(\mathrm{mol}^{-1}\right.$ )" should be "average adsorption loading (molecules per cell)".

(3) Page 3230, right column, line 3, "average adsorption loading $\left(\mathrm{mol}^{-1}\right)$ " should be "average adsorption loading (molecules per cell)".

(4) Table S1, "adsorption loading ( $\mathrm{L} / \mathrm{mol})$ " should be "adsorption loading ( $\mathrm{L} /$ molecules per cell)".

(5). The corrected Fig. 1, Fig. 6, and Fig. S12 are provided below: 


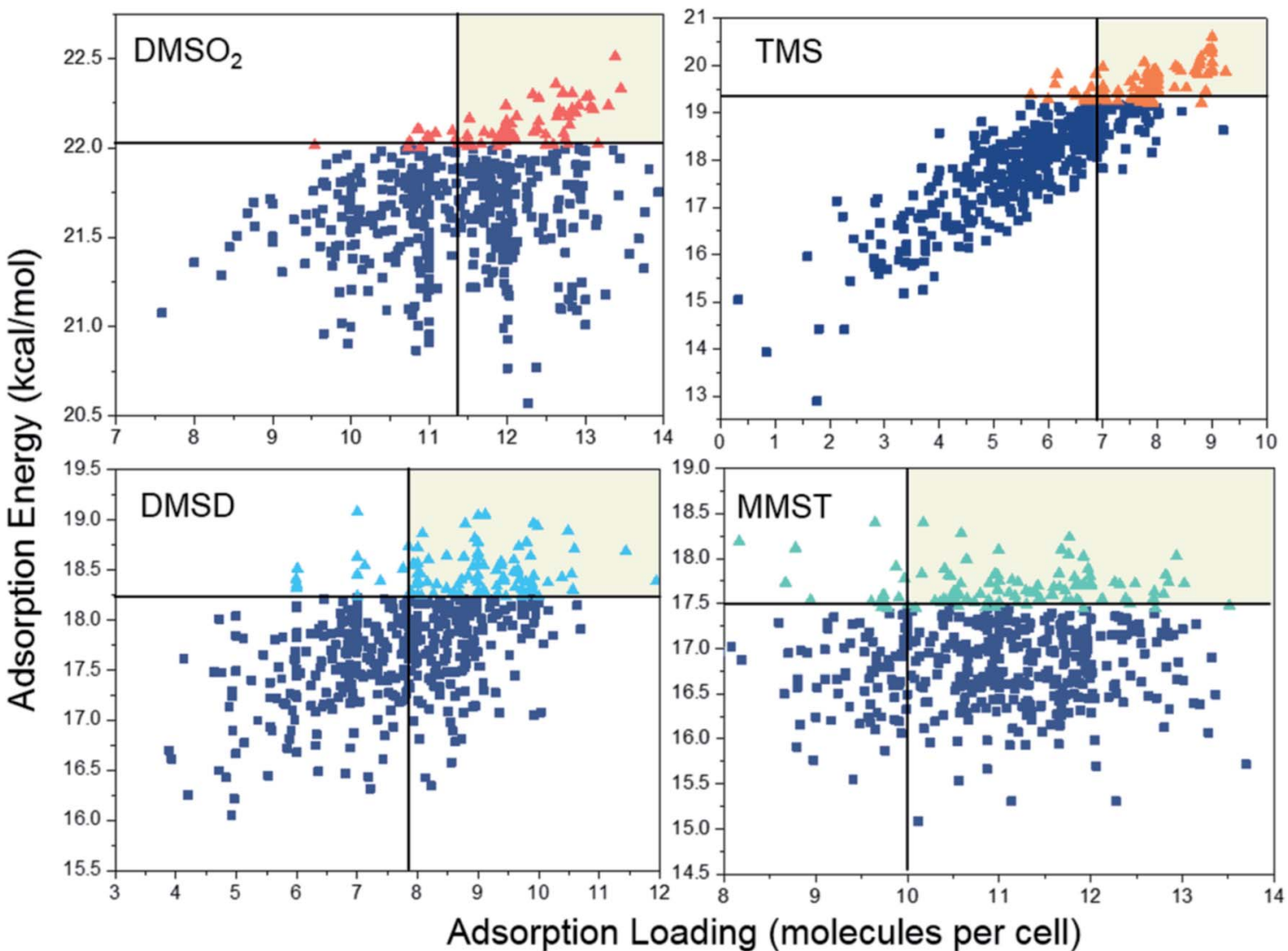

Fig. 1 The average adsorption energy and loading values of 500 PSZs towards four PCs, where triangles represent the top 20\% zeolites (class-1) ranked by adsorption energy, while the square points are the other $80 \%$ zeolites (class-0), and the light yellow sections denote the top $90 \%$ class1 zeolites ranked by adsorption loading.
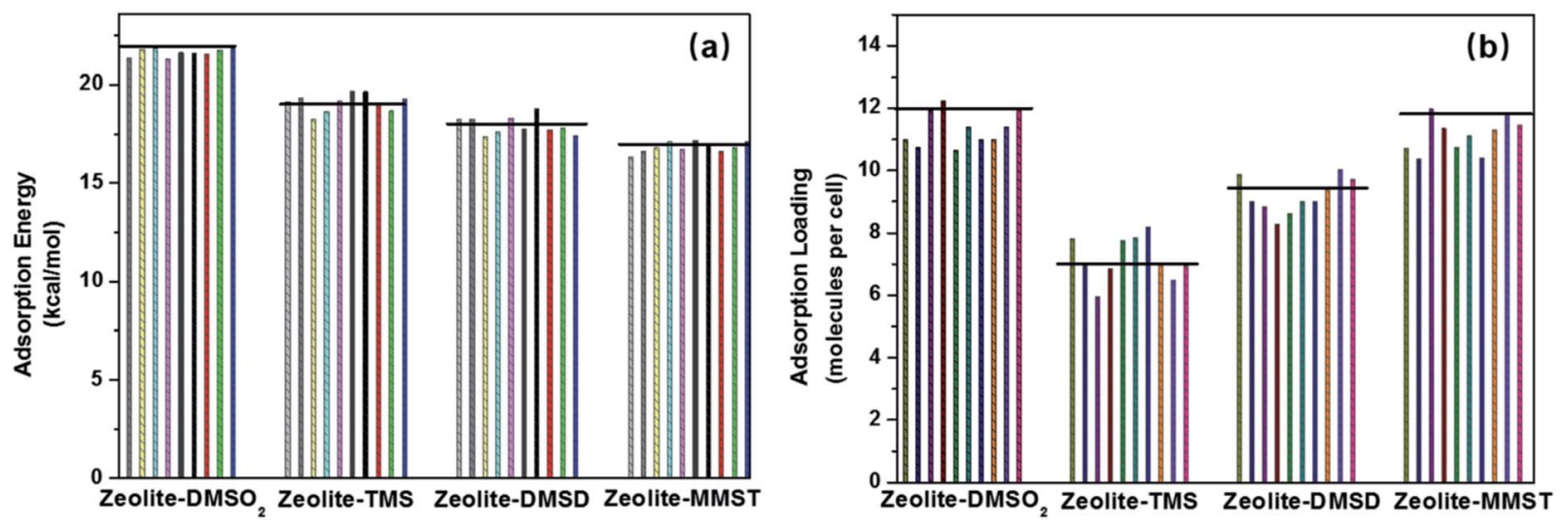

Fig. 6 (a) The adsorption energies and (b) adsorption loading of the first set of randomly chosen 10 zeolites from the predicted 230 four-class-1 zeolites, where the upper lines correspond to the top $20 \%$ adsorption energies (a) and top 30\% adsorption loading (b) in the training data of 500 . 

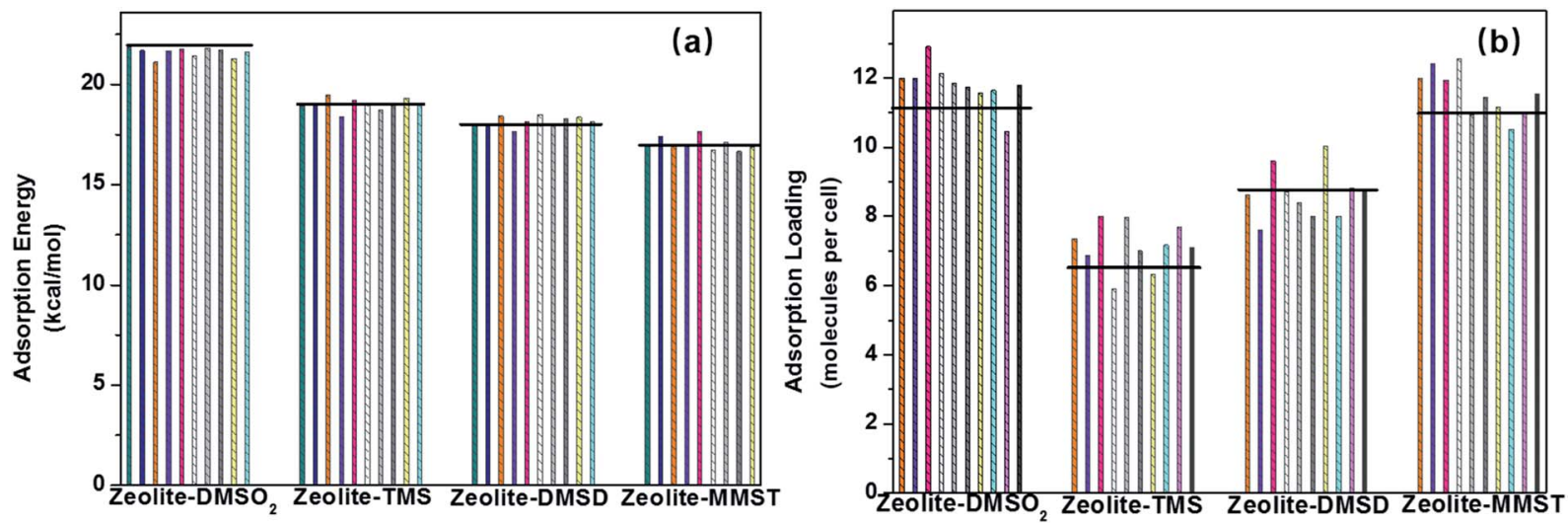

Fig. S12 (a) The adsorption energies and (b) adsorption loading of the second set of randomly chosen 10 zeolites from the predicted 230 fourclass -1 zeolites, where the upper lines correspond to the top $20 \%$ adsorption energies (a) and top $30 \%$ adsorption loading (b) in the training data of 500 .

The Royal Society of Chemistry apologises for these errors and any consequent inconvenience to authors and readers. 